\title{
Archaeometric characterization and conservation of two Bronze-Iron Age jars from Sahab archaeological site, Jordan
}

\section{Archaeometric characterization and conservation of two Bronze- Iron Age jars from Sahab archaeological site, Jordan}

\author{
Khaled Al-Bashaireh ${ }^{1}$, Abdelrahman Elserogy ${ }^{2}$, Moawiyah Ibrahim ${ }^{3}$ \\ 1-Department of Archaeology, Yarmouk University, Postal code 211-63, Irbid, Jordan, email: \\ khaledsm@email.arizona.edu (correspondent author). \\ 2-Fayuom University, faculty of Archaeology Department of Conservation and Management of \\ Cultural Heritage, Yarmouk University, Postal code 211-63, Irbid, Jordan, email: \\ xserogy@yahoo.com \\ 3-Professor of Archaeology and Cultures of the Ancient Near East, P.O.Box 815584, 11180 \\ Amman, Jordan, email: moawiyahi@gmail.com
}

\begin{abstract}
The aim of this study is to assess the condition, characterize the production technology and conserve two large burial jars (pithoi) excavated during the early years of the 1970s from Sahab, Jordan. The jars, that showed physical and chemical deterioration signs, were dated to the Iron Age I based on their style (collared-rim) and accompanied artifacts. In order to determine the date of the jars' use for burial purposes, a bone femur found in the first jar was radiocarbon dated. The study examines the jars using magnifying lenses, polarized light and scanning electron microscopes and X-ray diffractometer. The radiocarbon date placed the use of the jars for burials during the Late Bronze-Early Iron ages which agrees with their archaeological date. The collected data show that the first jar is temepered with local chert and fired at temperatures below $850^{\circ} \mathrm{C}$. The presence of gehlenite and vetrification in the second jar indicates a firing temperature above $850^{\circ} \mathrm{C}$. The jars were dry, and then wet cleaned mainly using water, but the chelating agent EDTA was used in certain circumstances. The cracks of sample 1 were filled with a Paraloid B-72 and glass microballoons based-colored paste. A Paraloid based-coat was used to protect them during their display in the museum.
\end{abstract}

\section{Introduction}

Sahab is located about $12 \mathrm{~km}$ southeast Amman on the modern and ancient road to the desert castles including (among others) Muwaqqar, Mshatta, Harraneh and Qseir Amra (Fig. 1). Rescue excavations that took place at the site between 1972 and 1980 were sponsored by the Department of Antiquities and later (in 1980) by Yarmouk University. Sahab has a long history of occupation extending from the Late Neolithic/Chalcolithic $\left(5^{\text {th }}\right.$ and $4^{\text {th }}$ millennia $\left.\mathrm{BC}\right)$ to the Late Iron Age. After the $6^{\text {th }}$ century BC, the site was probably abandoned until the Medieval Arabic period $\left(11^{\text {th }}-13^{\text {th }}\right.$ century AD), evidenced by Ayybid-Mamluk handmade pottery sherds. Another occupational gap ran from the $13^{\text {th }}$ to the $19^{\text {th }}$ centuries, at which time the present inhabitants moved to the site (Ibrahim 1972). 


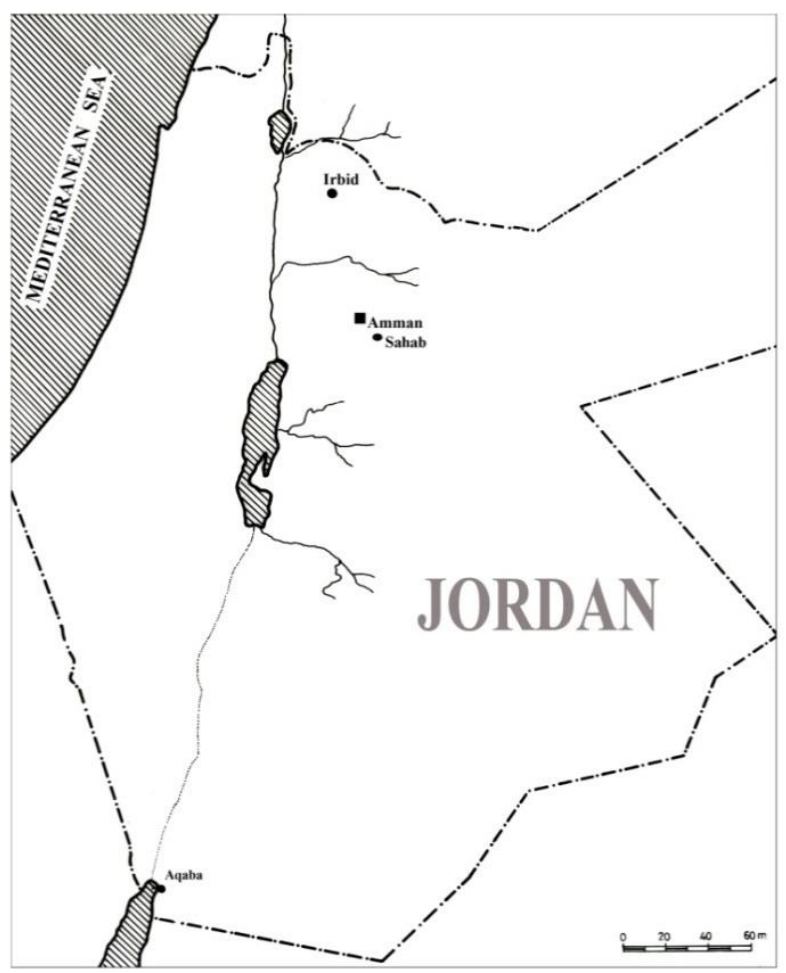

Fig. 1 location map.

A group of eight jars with cutoff mouths used for burials were uncovered from a cave (Tomb 1) in area $\mathrm{C}$ together with rich Iron I deposits including scarabs, alabaster vases, pottery and metal objects. The jars were arranged in four pairs forming an M-shape in which the mouths of each pair were contiguous and facing each other (Fig. 2). These jars are similar to collared-rim jars excavated from other areas at Sahab, especially from Area A and were dated to the Early Iron Age (for more details see Ibrahim 1972, 1978). The jars are ovoid rounded with two handles attached vertically above the middle of the body, joining the wide and slightly convex shoulder, for parallels see Ibrahim 1970: page 30-31 and Ibrahim 1978.

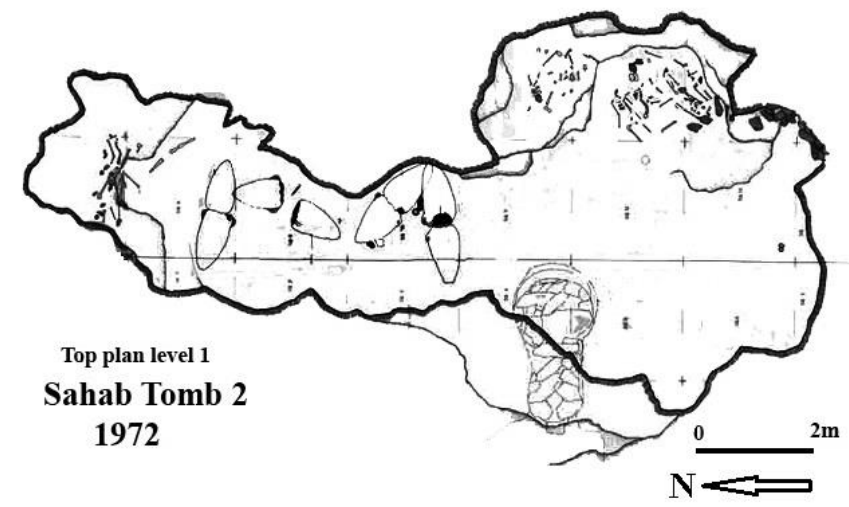

Fig. 2 A top plan of the tomb 2 in area $\mathrm{C}$ showing the jars distribution in M-shape (Ibrahim 1972). 


\section{Archaeometric characterization and conservation of two Bronze-Iron Age jars from Sahab archaeological site, Jordan}

Only two of the above mentioned eight jars from Sahab were stored at the storage facility at Yarmouk University, Jordan. One of the two jars (jar 1) comprised human bones of skeletons buried in it (see Abu Dalou et al. (2014) for details). This research studied the two jars after a decision taken to display them in the Museum of Jordanian Heritage at Yarmouk University. It reports a radiocarbon date of a bone from jar 1 in order to examine the date of the archaeological use of the jars for burial purposes and provides archaeometric characterizations of the two jars and scientific procedures performed to maintain, conserve and display them in the Museum.

\section{Materials and methods}

One tooth of an adult female and one bone femur of an infant were collected from the first jar (jar 1) for radiocarbon dating. One small broken pottery sherd was collected from each jar for archaeometric analyses including petrographic and scanning electron microscopy (SEM) and X-ray diffractometry (XRD). In addition, the mineralogical composition of the jars' encrustations of the two jars was examined by XRD. Then, conservation and maintenance treatments including cleaning, gap filling and coating were performed based on the results of the archaeometric analyses. At the end, both jars were displayed in the Museum of Jordanian Heritage at Yarmouk University, Jordan.

\section{a) Radiocarbon dating}

The bone and tooth samples were chemically pretreated and dated at the NSF-Arizona Accelerator Mass Spectrometry (AMS) Laboratory. Initially, surface contaminants of the sample were removed by sonicating them in deionized water (for more details see Al-Bashaireh et al. 2010, 2011). After drying, the inner part of the bone and tooth dentine were exposed with a milling bit and then ground. An amount of 500-600 mg of each powder was acid-base-acid pretreated using a semi-automated system. After the completion of the pumping sequence, the acid-base-acid treated powders were transferred into borosilicate test tubes, and then the total solution volume was reduced to about $3 \mathrm{ml}$, while gelatinizing the insoluble collagen fraction from the samples at $70^{\circ} \mathrm{C}$ overnight rendered it soluble. This solution was filtered through prewashed $0.45 \mathrm{~mm}$ particle retention glass microfiber filters. The filtrate was recovered and lyophilized in a Speedvac S110 centrifugal evaporator connected to a Varian oil-less Scroll pump. Then 3-10 mg of the collagen was combusted, graphitized, and finally delta carbon-13 and carbon-14 were measured. Date calibration was accomplished using the IntCal04 data set (Reimer et al. 2009) and OxCal 4.10 calibration software (Bronk Ramsey 2009). The calibrated ages are presented at the $68.2 \%$ and $95.4 \%$ confidence intervals.

\section{b) Archaeometric characterization}

Three methods were utilized in the characterization of the two jars:

1- X-ray diffraction examined the mineralogical composition of the two jars and their encrustations on bulk powders. The XRD data were collected using a Shimadzu Lab X, 6000 X- 
Ray Difractometer under the following conditions: CuK $\alpha$ radiation $\left(1.5418 \mathrm{~A}^{\circ}\right)$ with $30 \mathrm{kV}$, 30mA energy and Graphite Monochromatic.

2- Petrographic analysis investigated the mineralogical composition and textural variability of the two samples. One thin sections of each jar was prepared and examined using the LEICA Polarized Microscope equipped with a LEIZA DMLSP ICC 50HD digital camera to capture images. Thin sections were made by cutting the desired section from the sample with a diamond saw. One side of the cut section was polished and mounted on a microscope glass slide using an epoxy resin. The thickness of the mounted section was reduced by grinding it down, and finally polished to a uniform thickness of about 30 microns. The thickness of the sections was examined by the colors of the minerals under the microscope. Thin section preparation and XRD analyses were carried out at the laboratories of the faculty of archaeology and anthropology at Yarmouk University, Irbid, Jordan.

3- Scanning electron microscopic-energy dispersive spectroscopic (SEM-EDS) analyses were carried out at Mango Center for Scientific Research, University of Jordan using INSPECT F50 microscope equipped with a high electron beam resolution Schottky field emission source up to $3 \mathrm{~nm}$ at $1 \mathrm{kV}$ and $1 \mathrm{~nm}$ at $30 \mathrm{kV}$ and a Bruker Quantax EDS microanalyser-X flash silicon drift (SDD) detector. It works at high vacuum of about $6 \mathrm{e}^{-4}$ Pascal and gives images magnified up to about 1000000x. The samples were coated with platinum using an Emitech K550X sputter coater, and then image and qualitative analyses were performed to define the groundmass microstructure, inclusions and the degree of the vitrification of the groundmass of the two jars following the indications proposed by Tite and Maniatis (1975) and Tite et al. (1982).

\section{Results and discussion}

\section{Radiocarbon dating}

Radiocarbon dating determination is presented in Table 1 and Fig. 3. Unfortunately, the tooth of the adult femur did not provide enough collagen for dating; therefore, the bone femur remained the only datable material for the use of the jar. The radiocarbon determination of the sample is $2995 \pm 50 \mathrm{BP}$ and its calibrated dates at $95.4 \%$ are $1393-1336 \mathrm{BC}(11.8 \%)$ and $1324-$ 1056BC $(83.6 \%)$, while at $68.2 \%$ are $1367-1364 \mathrm{BC}(1.1 \%)$ and $1292-1128 \mathrm{BC}(67.1 \%)$. This date (at $95.4 \%$ ) covers the last 200 years of the late Bronze period and the first 150 years of the Iron period; therefore, the sample could be dated to the Late Bronze-Early Iron period. This date indicates that the first jar was used during this period for burial purposes following earlier traditions started during the late Neolithic period (Al-Shorman and Khwaileh 2011). Because the two jars were in the same context facing each other in the same cave, the radiocarbon date covers both of them. The radiocarbon date of the jars accords with the archaeological date of the jars to Iron Age I (1200-900BC). 
Table 1 Radiocarbon (BP) and calibrated dates (BC/AD) at 68.25 and 95.4 percent of Sahab bone femur ( $\mathrm{F}$ = fraction of modern, $\mathrm{SD}=$ standard deviation).

\begin{tabular}{|c|c|c|c|c|c|c|}
\hline Lab. n. & $\begin{array}{l}\text { Materia } \\
1\end{array}$ & $\begin{array}{l}\delta^{13} \mathrm{C} \\
(\%)\end{array}$ & $\mathrm{F} \pm \mathrm{SD}$ & $\begin{array}{l}{ }^{14} \mathrm{C} \\
\text { age } \\
\pm \\
\mathrm{SD}(\mathrm{BP} \\
)\end{array}$ & $\begin{array}{l}\text { Calibrated age } \\
\text { BC/AD }(68.2 \%)\end{array}$ & $\begin{array}{l}\text { Calibrated age } \\
\text { BC/AD }(95.4 \%)\end{array}$ \\
\hline $\begin{array}{l}\text { AA928 } \\
11\end{array}$ & $\begin{array}{l}\text { Bone } \\
\text { femur }\end{array}$ & $\begin{array}{l}- \\
19.3\end{array}$ & $\begin{array}{l}0.6888 \pm \\
0.0043\end{array}$ & $\begin{array}{l}2,995 \\
\pm 40\end{array}$ & $\begin{array}{l}1367-1364 \mathrm{BC} \\
(1.1 \%) \\
1292-1128 \mathrm{BC} \\
(67.1 \%)\end{array}$ & $\begin{array}{l}1393-1336 \mathrm{BC} \\
(11.8 \%) \\
1324-1056 \mathrm{BC} \\
(83.6 \%)\end{array}$ \\
\hline & 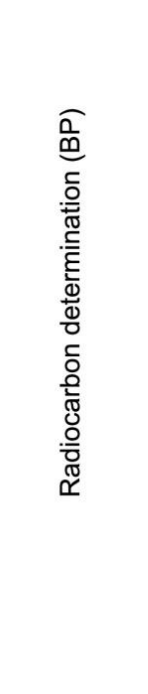 & 唯 & $\frac{1}{1400}$ & $\begin{aligned} 120 \\
\text { Salibrated d }\end{aligned}$ & $\begin{array}{l}\text { c curve (Remere eta 2 2013) } \\
\text { Jate(2995,50) } \\
68.2 \% \text { probability } \\
1367(1.1 \%) \text { 1364calB } \\
1292(67.1 \%) 1128 \mathrm{call} \\
95.4 \% \text { probability } \\
1393(11.8 \%) \text { 1336cal } \\
1324(83.6 \%) \text { 1056call }\end{array}$ & $\frac{1}{800}$ \\
\hline
\end{tabular}

Fig. 3 The radiocarbon date of the Sahab bone uncovered from the first jar.

Al-Shorman and Khwaileh (2011) stated that the use of jars for burial practices in Jordan started in the Late Neolithic Period, continued to be used during subsequent periods including the Chalcolithic and Early Bronze Ages, used in lesser extent in the Middle Bronze Age, while it stopped in the Late Bronze Age or was not found except the one case of Tubb et al. (1996). The results of this study present a new evidence that jar burial traditions were also used during the Late Bronze - Early Iron Ages. Ibrahim (1978) argued that burial jars of the Early Iron Age were in use alongside anthropoid clay coffins, wooden coffins and the common shaft tombs and rockcaves.

\section{Macroscopic description of the two jars}

The shapes and dimensions of the jars are shown in Fig. 9. They are large (pithoi) and thick walled $(1.4 \mathrm{~cm})$ with removed mouths (but still have the two handles) to fit burial purposes. The fabric of the first jar is coarse and reddish brown but covered with white encrustation on most of its surface and soil on some parts. Part of its inner side has remains of a thin soil layer and some bones, which might indicate that the buried skeleton was placed on this part. The jar 
has two opposite vertical fractures that cross two thirds of the jar from the shoulder downwards. The maximum aperture of the fracture at the shoulder is about $1 \mathrm{~cm}$. The fabric of the second jar is fine-medium and beige to dark reddish brown. It is highly deteriorated, but free of fractures, and has a thin layer of soil and white encrustation on its inner and outer sides.

\section{Raw materials}

Petrographic examination of both samples showed two different fabrics. The first sample (jar) has a coarse to very coarse fabric of about $40-45 \%$ non plastic materials. Its plastic components have a light reddish brown color and comprise fine quartz and opaques. The main non plasctic materials identified are fragments of chert $(\sim 25 \%)$ and micritic limestone $(\sim 8 \%)$ (Fig. 4A). XRD analyses confirmed microscopic examinations and showed that the quartz (mainly from chert) is the major mineral phase, while plagioclase, hematite, calcite and apatite are minor mineral phases (Fig. 5). The sample has about $10 \%$ of elongated voids and about $5 \%$ of iron oxide surrounding some grains or staining others. Micritic limestone fragments are medium in grain size and subrounded to rounded, while chert fragments are coarse to very coarse in grain size and angular to subangular in shape. The presence of minor amount of calcite might be explained by the SEM analyses that showed partial filling of secondary calcite in the voids of the jar during its burial (Fig. 6E). The high percentage, coarse grain size and angularity of chert grains suggest that they were likely crushed or ground prior to their intentional addition to the clay. It is likely that the chert fragments are from the dominant rock formations present in the area mostly from the Umm Rijam Chert Limestone or the superficial deposits mainly formed of (among others) chert clasts which either outcrop in the adjacent area or along the nearby Wadis (Fadda 1991).

The second sample (jar) has a fine to medium fabric (Fig. 4B). Its plastic components have a dark brown clay and comprise less than $5 \%$ of fine rounded quartz grains and opaques. It is characterized by the presence of high percentage of voids (about 40\%) which are mainly rounded to subrounded, but some of them are elongated. It has about $10 \%$ of medium rounded to subrounded grains of micritic limestone, while secondary calcite grains replaced parts of many micrite grains and precipitated (during the jar's burial in the soil) in some voids or at the edges of others (Fig. 6D). XRD analyses of this sample showed the presence of apatite, calcite and quartz as major phases, plagioclase and hematite as minor phases, and less amount of gehlenite phase (Fig. 5). These phases reflect the presence of non plastic materials including quartz, limestone and opaques (iron oxide). The apatite, most probably, is a strong indication for bones and teeth remains in the clay used for its production. The outer porous texture (tiny hollow cavities) and chemical composition of some fragments analyzed by SEM-EDX confirmed the presence of fine bone fragments in the paste of the sample (Fig. 6B1,B2). It is very likely that the clay used in the production of the second jar was weathered from the Balqa group (among others) that comprises Al-Hisa Phosphorite Formation which is rich in phosphate rocks (Fadda 1991). Similar conclusion was proposed by Al-Shorman and El-Khouri (2013). 

archaeological site, Jordan
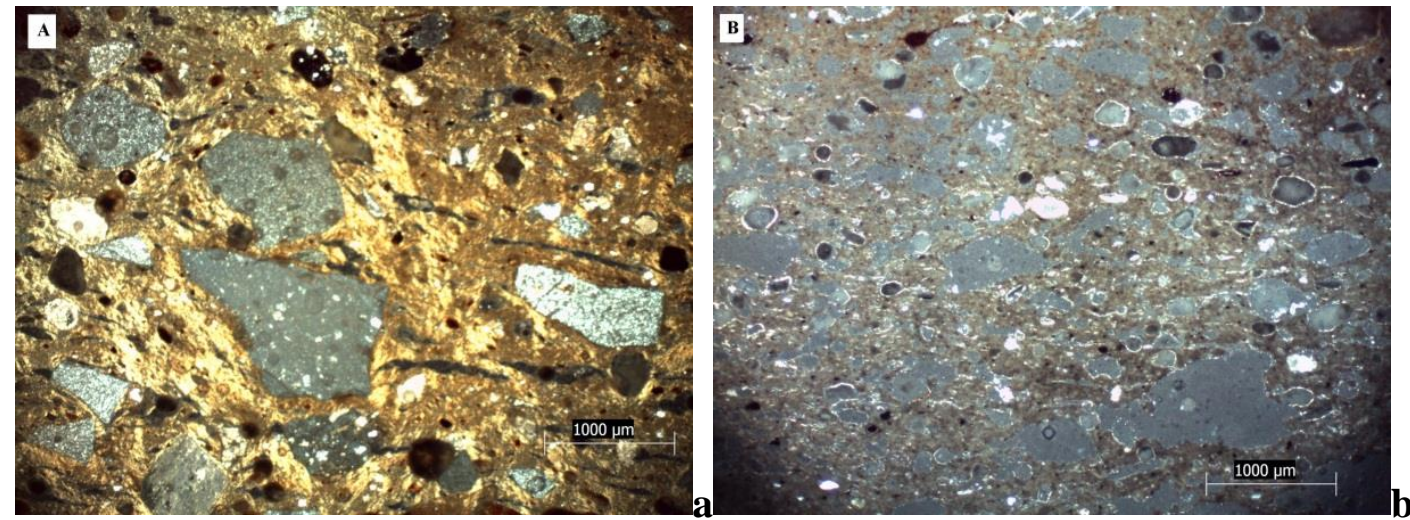

Fig. 4 photomicrographs show (A) the coarse fabric of sample 1, chert temper and subparallel elongated voids; (B) the fine-medium fabric of sample 2, secondary calcite, and alignment of the voids and calcite grains.
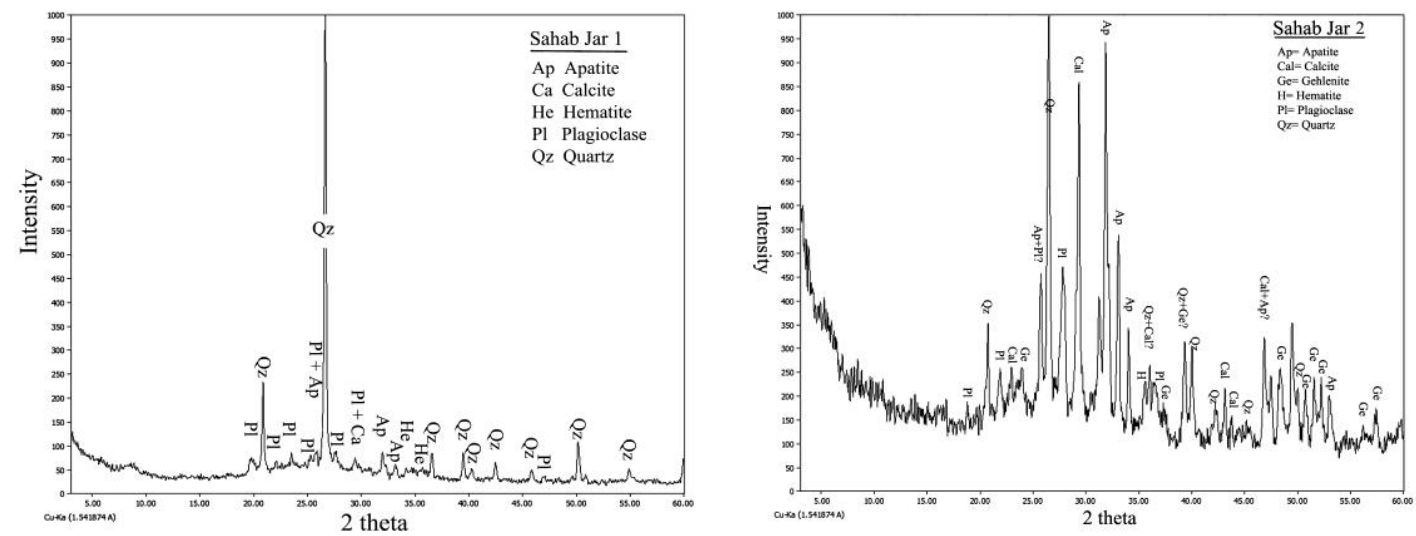

Fig. 5 XRD spectra showing the mineral composition of the two samples.

\section{Shaping of the jars}

Macroscopic examination of the outer and inner surfaces of the two jars showed the joins between flattened coils used in building the jars. The smoothing away of the joins was insufficient to mask them completely. Petrographic examination showed that the samples comprise thin elongated and sub-parallel voids. The long sides of the tempers and voids show a more or less the same distinct orientation (Fig. 4) which is most probably subparallel to the potter's rotating direction of the coils (Peterson and Betancourt 2009). In addition, SEM images showed longer subparallel voids of sample 1 than those of sample 2 (Fig. 6C). This shaping technique is similar to those of the Late Bronze Age pottery from Deir 'Alla (Franken 1992) and Baq'ah (Glanzman and Fleming 1986). The results support the argument of Wood (1990) and Killebrew (1998) that the shaping of the pottery during late Bronze Age lacked wheel-throwing and was substituted by the coil-building technique. 


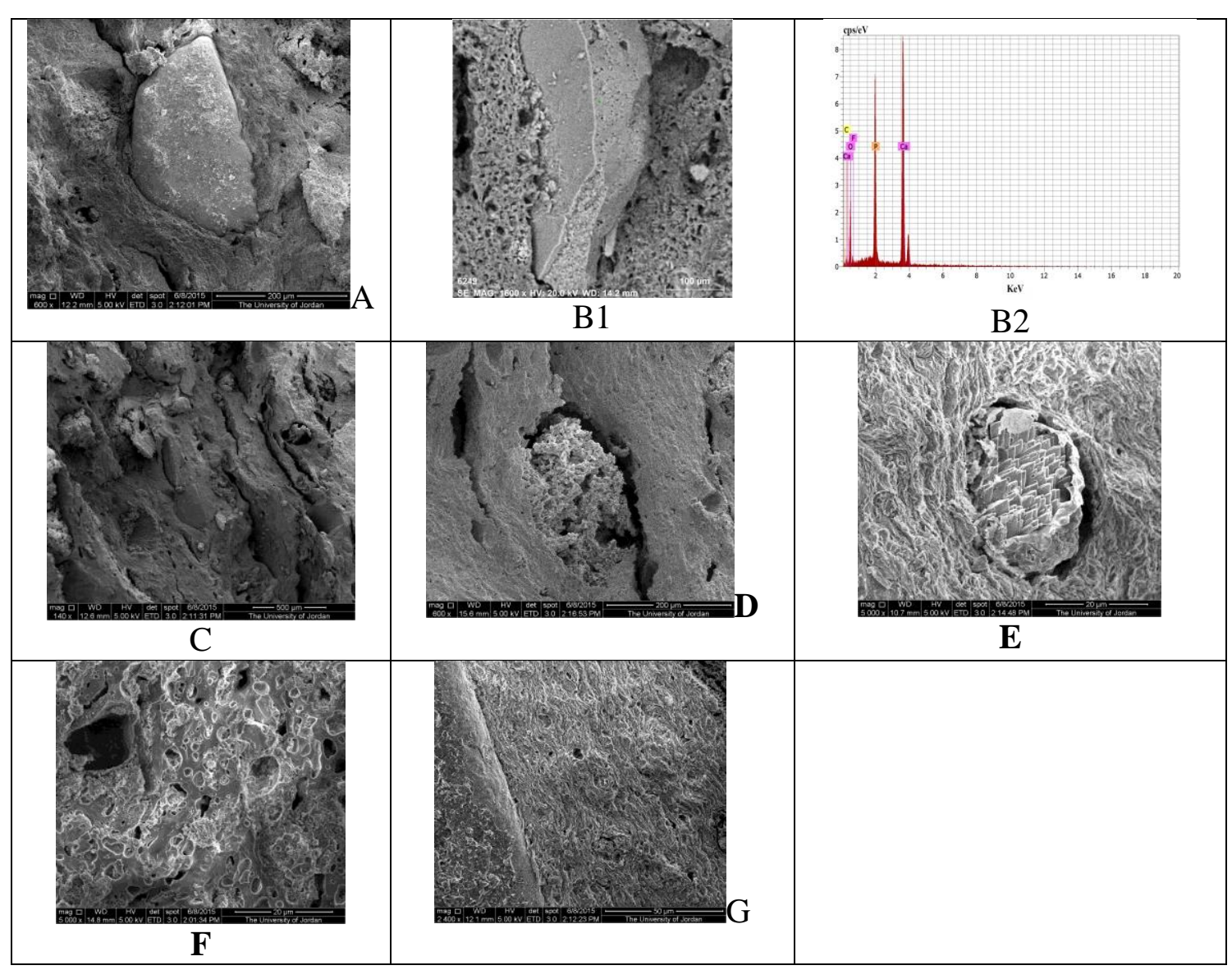

Fig. SEM micrographs and EDS analysis: 6A shows cracks and elongated voids around the coarse grains and sharp contacts of a subrounded quartz grain with the matrix, 6B1 the porous texture a bone fragment, 6B2 EDS analyses of the grain in 6B1 showing phosphate composition of a bone fragment, $6 \mathrm{C}$ sub-parallel elongated voids, $6 \mathrm{D}$ a void filled with secondary calcite, $6 \mathrm{E}$ calcite rhombs filling a void space, $6 \mathrm{~F}$ partial melting of sample 2, $6 \mathrm{G}$ compacted clay lamella of sample 1.

\section{Firing of the jars}

XRD analyses showed the presence, in both samples, of untransformed or partially decomposed calcite (micrite) particles that decompose between $600-850^{\circ} \mathrm{C}$ which might initially indicate firing temperatures below $850^{\circ} \mathrm{C}$. However, one should keep in mind that carbonates decomposition depends not only on the duration time of firing and the kiln's temperature and atmosphere, but also their amount and grain size (Rice 1987). SEM analyses of sample 1 shows dense compacted clay laminar sheets, but no evidence of sintering or partial melting (Fig. 6G). The laminar habit of the clay, large voids and absence of partial melting in sample 1 indicate a firing temperature between 700 and $800^{\circ} \mathrm{C}$ (Cultrone et al., 2001). High temperature minerals such as spinel, ghehlenite, cristobalite and mullite were not detected by XRD analyses which support the above result of a firing temperature not exceeding $850^{\circ} \mathrm{C}$ for the first jar (Grim 1968, p.596). On the contrary, the presence of gehlenite in sample 2 indicates its firing temperature 


\section{Archaeometric characterization and conservation of two Bronze-Iron Age jars from Sahab archaeological site, Jordan}

between $850^{\circ} \mathrm{C}$ and $950^{\circ} \mathrm{C}$ (Riccardi et al. 1999). However, the small amount of ghehlenite, the presence of medium grains of primary calcite and the high percentage of spherical voids indicate that the firing temperature of the second jar was a little higher than $850^{\circ} \mathrm{C}$, a temperature that apatite withstands (Maritan et al. 2006). SEM results of sample 2 shows partial melting and initial vitrification of the groundmass (Fig. 6F) supporting the above conclusion. It is probable that this temperature decomposed fine-grained calcite into quicklime and carbon dioxide, then the quicklime reacted with clay minerals to form gehlenite (Maggetti 1994, Riccardi et al. 1999). It is worth mentioning that unreacted quicklime absorbs carbon dioxide and forms secondary calcite that mainly precipitates in the voids (Fig. 6D).

These results are in accordance with those of Al-Naddaf (2006) and Shoval et al. (2006). Al-Naddaf (2006) studied 41 samples of Late Iron Age pottery including seven storage jars from Tell Johfiyeh and concluded that their firing temperature did not exceed $800^{\circ} \mathrm{C}$. Shoval (2006) showed that the firing temperature of the Iron Age storage jars from Galilee was about 650$750^{\circ} \mathrm{C}$.

The light red and brown colors discussed above may indicate an oxidizing atmosphere during the firing of the first jar, while the dark grey core and light brown-beige outer surfaces indicate a semi-oxidizing or semi-reducing condition (Rye 1981).

\section{Conservation processes}

Naked eye and magnifying lens investigations showed that the two jars are affected by soluble and insoluble salt encrustations and adhering bones and hard soil and dirt. Soluble salts (such as chlorides) caused encrustations and partial destruction of the pottery fabric, while carbonates (such as calcite) caused exfoliation on jars' surfaces (Cronyn 1990) (Fig. 7A-B). In addition, the first jar is affected by a structural damage mainly of two opposite long and smallmedium size cracks (Fig. 8). Most probably the cracks were formed when the mouth of this jar was removed or by erroneous practices of lifting, transport, handling and/or storage.

It is worth noting that the jars were stored directly as excavated without any conservation treatment for decades. The storage facility was not appropriate to house archaeological collections, because it lacks required storage controls of temperature, humidity, light ...etc. The cracks in both sides of the first jar endanger its physical integrity and the adhering salts and soil endanger the two jars' chemical stability; therefore, rapid interventive conservation was necessary (Buys and Oakley 1993). Initially, conservation treatment started with cleaning in order to remove the foreign materials from the jars' surfaces, then the cracks were filled and finally the jars were coated to display them in the Museum of Jordanian Heritage at Yarmouk University, Jordan.

\section{A- Cleaning}

Because salt and soil deposits on several spots of the jars were very hard, great care was taken during the cleaning of the jars' surfaces and broken edges. Cleaning was often carried out under magnification to monitor the effect of this process and avoid the removal of the original 
fabric of the jars. Special care and focused monitoring was given during the cleaning of the second jar which appeared more deteriorated than the first jar.

Both jars were initially dry cleaned. The jars were carefully placed on a soft surface and the minimum necessary pressure was applied in their cleaning process. Mechanical cleaning used air blower and soft and stiff brushes to remove soil and dirt which were loose or weakly adhered to the surface of the jars. XRD analysis of the white encrustation deposited on the jars' surfaces showed that gypsum $\left(\mathrm{CaSO}_{4} \cdot 2 \mathrm{H}_{2} \mathrm{O}\right)$ and calcite $\left(\mathrm{CaCO}_{3}\right)$ are its major and minor components, respectively. Because of the softness of gypsum, it was removed by dry cleaning.

Scalpels or needles were used to remove harder deposits and encrustations. On the contrary, plastic and wooden tools were used for dirty fragile surfaces and broken edges. Mechanical dry cleaning was preferred because it is easier, faster and applied without fear of any penetration of soluble dirt into the jars' pores especially into those of the first jar.

Further mechanical dry cleaning of hard sticky soils and salts was avoided in order to protect the original fabric of the jars. Wet cleaning was utilized in these cases using distilled water which is safe, cheap and effective for removing surface deposits and dirt (Buys and Oakley 1993). Hardened deposits were picked and removed by continuous gentle rolling of wet cotton swabs across the jars' surface (Plenderleith and Werner 1971) (Fig. 7).

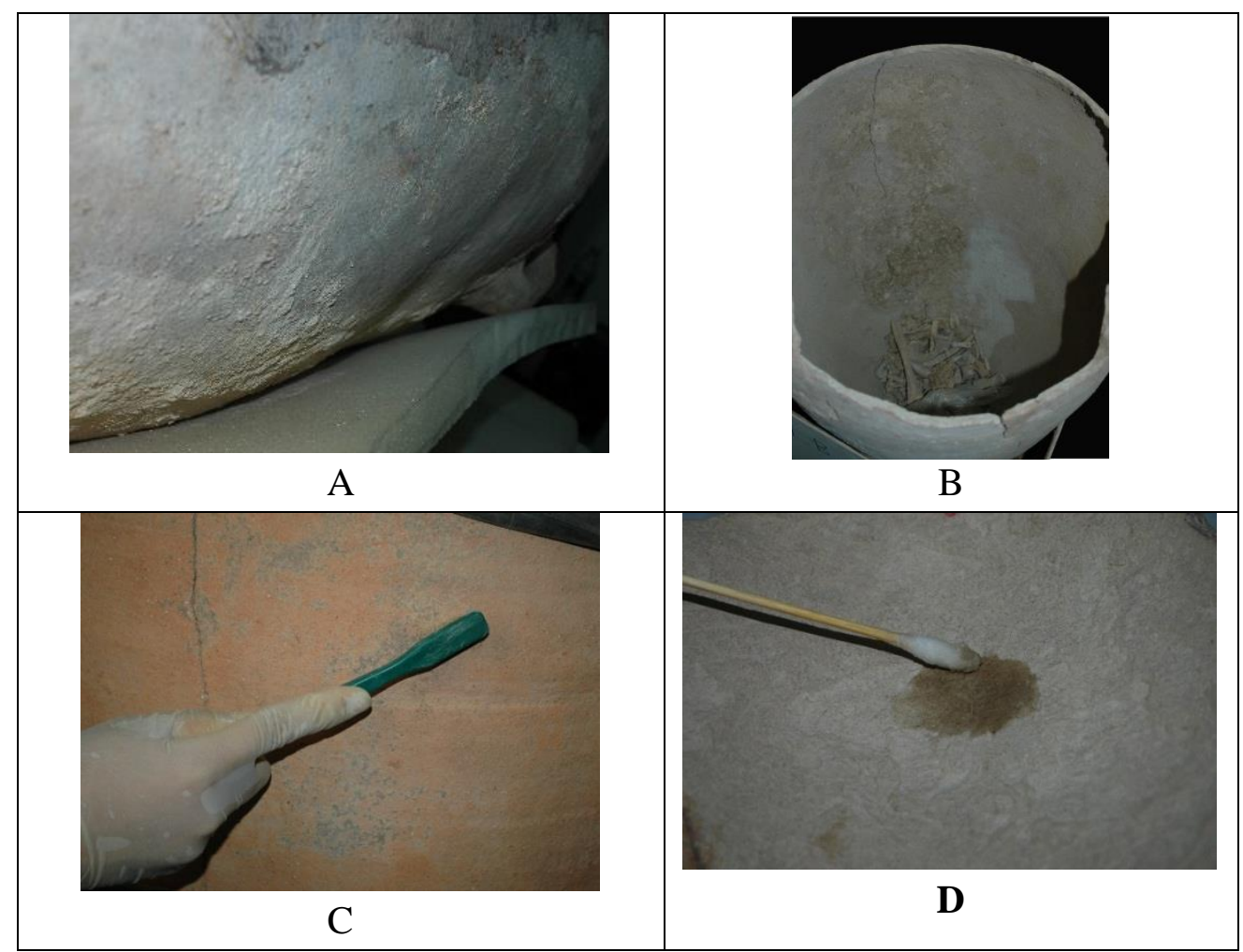

Fig. 7 shows mechanical and wet cleaning. 


\section{Archaeometric characterization and conservation of two Bronze-Iron Age jars from Sahab archaeological site, Jordan}

Wet (water) cleaning was ineffectual in certain cases of hard dirt; therefore, a wet cleaning using organic solvent was used. Alcohol was added to the water to increase its softening effect on hard dirt and weaken their contact with the jar's material. A 50:50 solution of distilled water and Industrial Methylated Spirits (IMS) was locally applied using a paintbrush. A squareended paintbrush was then used to remove the softened soil. Swabs of cotton were avoided in this stage because cotton fibers stick to roughened surfaces.

Hard calcite encrustation was removed using the chelating agent EDTA (ethylene diamine tetra-acetic acid) of low concentration (10\%). It is effective and more preferable for cleaning surface carbonate encrustations than hydrochloric acid which could dissolve other carbonates present in the jars.

\section{B-Gap filling}

As mentioned above, the first jar has two long opposite cracks at the top of the jar. The gap was cleaned and filled after bounding and tightening the jar parts together using a bike inner tube (Fig. 8). Adhesive tapes were fixed along the fractures to protect the jar surface from superfluous filling.

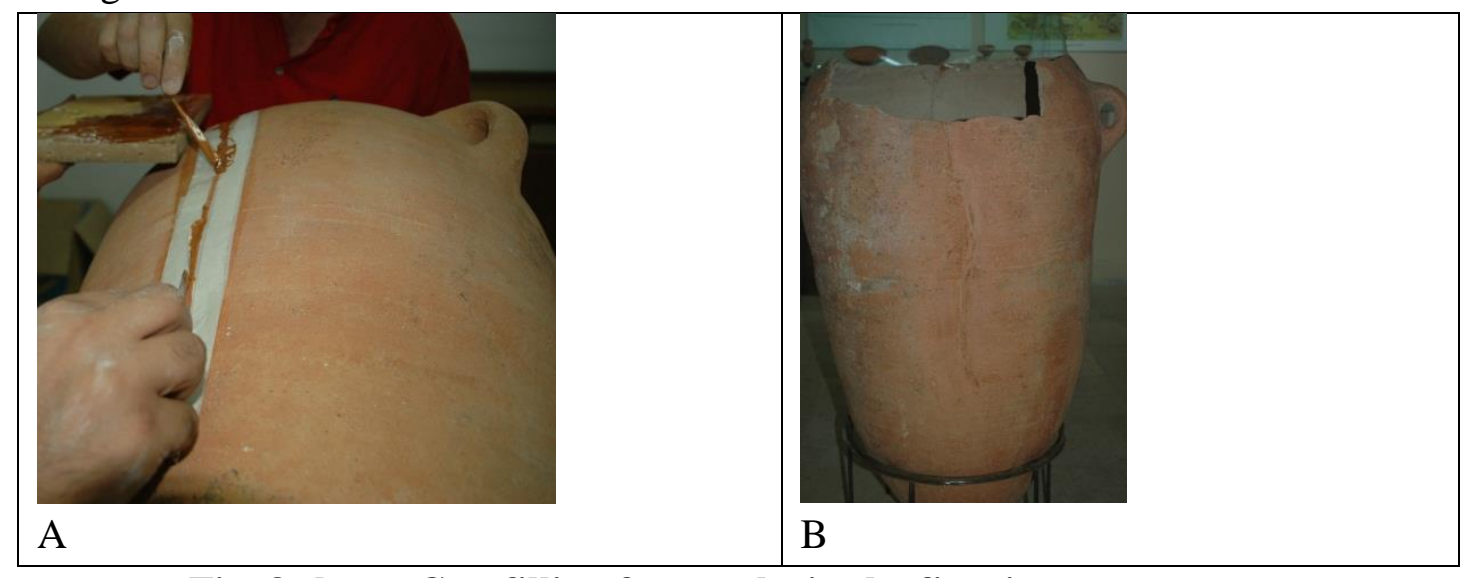

Fig. 8 shows Gap filling for cracks in the first jar.

The gap was filled with a paste of a mixture of paraloid B-72 and glass microballoons. A Paraloid B-72 solution in acetone is usually the best choice for joining fragments. The fill paste was made by dissolving a $25 \%$ solution of Paraloid B-72 in a mixture of $50 \%$ IMS with a $50 \%$ acetone, then the new mixture was mixed with glass microballoons in a proportion of $3: 1$, respectively. In order to distinguish the fill's color from that of the jar, the paste was colored light reddish using small quantities of iron brown (magnetite), red (hematite) and yellow (limonite) pigments before its addition. The desired color hue was reached after several mixing tests.

The fill paste is intermediate in hardness and strength, lightweight, strong, stable and reworkable, so it can be quickly dismantled using acetone with the minimal amount of pressure on the broken edges. In addition, it is inactive and do not absorb salts (Davidson and Brown 2012). 
A mould of dental wax was fixed on the inner side of the crack to support the paste and prevent its spread outside the gap.. Excess filling paste was removed and scrapped off by a knife before its complete hardening, then the surface of the paste was smoothed with a sponge to form a similar appearance of the jar's fabric (Smith, 1998). After the detachment of the wax sheet, the inner surface of the gap filler was smoothed by a polishing paper. It was noted that the color of the inner side of jar is darker than the filler's (and the outer side of the jar) color; therefore, after drying, the filler was colored with a stable water-based acrylic paint. This type of paint was selected because it will not be affected by the next coating layer formed mainly of paraloid (Dowman, 1970, Buys and Oakley 1993). Color matching gives an impression of the original appearance of the jar and prevents any confusion between the original and restored areas, especially the jars will be displayed in the museum (Fig. 2).

\section{C- Coating}

Visual and lens examination indicated that the jars' surfaces, due to deterioration factors, are fragile; therefore, they were protected from humidity, light ...etc by coating them with a Paraloid B-67 (an acrylic resin) which is recommended for pottery consolidation and coating purposes (Walker 1996). A diluted solution of 5\% concentration of Paraloid B-67 was dissolved in 50:50 IMS:acetone and applied by brushes. This mixture evaporates slower than the spirits alone, allowing greater penetration and bonding of the resin into the jars' texture before drying. The jars were placed beneath a polyethylene film for additional reduction in the evaporation rate of the solvents and the amount of B-67 drawn to the jars' surfaces during their drying.

\section{Conclusions}

The studied two large jars (pithoi) from Sahab were excavated and stored, without any conservation treatment, in an unsuitable environment for decades; therefore, they suffered different deterioration processes. The large dimensions of the jars and their similarity to the storage jars found in Sahab domestic houses indicate their primary function as storage jars, while the deliberate removal of their mouths and parts of the shoulders indicates their secondary function for burial practices. The radiocarbon date of the skeleton (bone) uncovered from the first jar and archaeological date of both jars indicate that the tradition of jars burial continued during the Late Bronze-Early Iron Ages. The difference in fabric and firing temperature and atmosphere of the two jars might indicate different pottery workshops or time periods for their production.

Chert temper was used in the first jar, while the apaptite in the second jar most probably derived from clays containing fish bones weathered from Al-Hisa Phospherite Geological Formation in the area. Most probably, the jars were made locally from local chert tempers and phospahtic clays because their large size limits their transportation for long distances (Shoval et al. 2006). The firing temperature of the first jar probably was below $850^{\circ} \mathrm{C}$, while the second jar was fired at temperatures slightly above $850^{\circ} \mathrm{C}$.

Initially, the jars were mainly dry and then wet cleaned mainly using water, but the chelating agent EDTA was used in certain circumstances. The fracture of sample 1 was filled with a colored paste made of a mixture mainly formed of paraloid B-72 and glass microballoons. Both jars were coated with a diluted Paraloid B-67 to protect them during their display in the museum (Fig. 9). 


\section{Acknowledgements}

The authors acknowledge the laboratory staff at the Faculty of Archaeology and Anthropology at Yarmouk University and Mr. Waddah Mahmoud from the SEM laboratory at the University of Jordan.

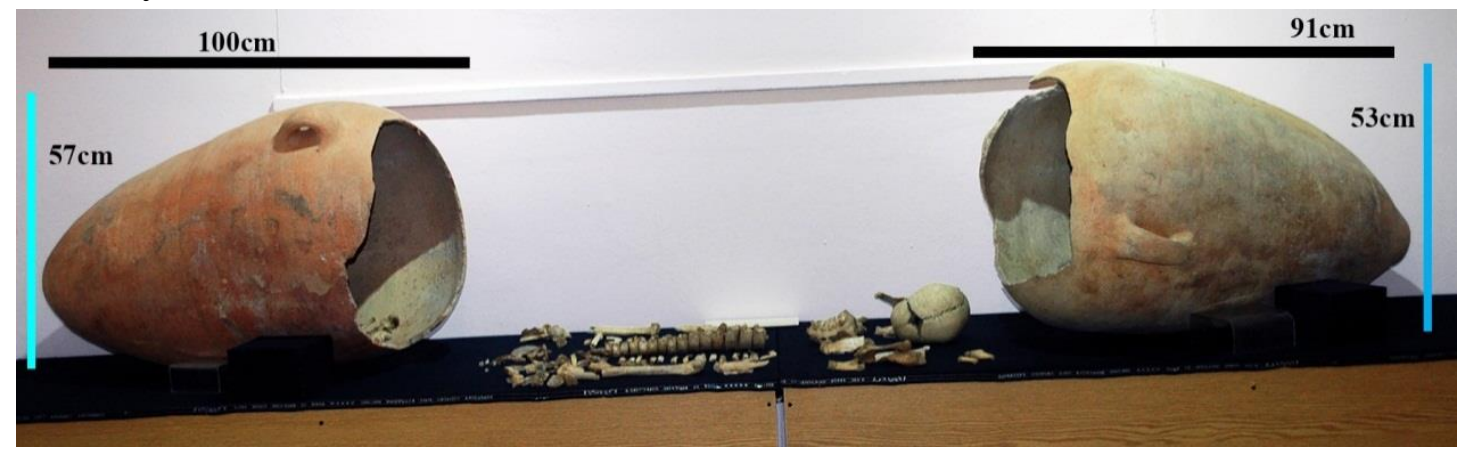

Fig. 9 shows the color and dimensions of the two jars displayed in the Museum of Jordanian Heritage, Yarmouk University, Jordan after conservation.

\section{References}

-Abu Dalou A, Elserogy A, Ibrahim M (2014) Burial Habits of Human Skeletal Remains in Jars from Archaeological Site of Sahab, Jordan: A Bioarchaeological and Conservation Study. The first international conference: Egypt and Mediterranean countries through ages -faculty of archaeology - Cairo Egypt. Vol. 3, pp. 7-19.

-Al-Bashaireh K, Al-Muheisen Z (2011) Subsistence strategies and palaeodiet of Tell al-Husn, northern Jordan: nitrogen and carbon stable isotope evidence and radiocarbon dates. J Archaeol Sci 38: 2606-2612.

-Al-Bashaireh K, Al-shorman A, Rose J, Jull TJA, Hodgins G (2010) Radiocarbon dating and palaeodiet reconstruction of the human remains from the archaeological site of Natfieh, northern Jordan. Radiocarbon 52(2-3): 645-652

-Al-Naddaf M (2006) Provenance and firing technology of Iron Age pottery of Tell Johfiyeh, Northern Jordan. Abhath al-Yarmouk, 22(4): 149-165.

-Al-Shorman A, El-Khouri L (2013) Archaeometric characterization of the Byzantine and Umayyad pottery at Barsinia, North Jordan. Mediterranean Archaeology and Archaeometry, 13(2): 207-220.

-Al-Shorman A, Khwaileh A (2011) Burial practices in Jordan from the Natufians to the Persians. Estonian J Archaeol 15: 88-108.

-Bronk Ramsey C (2009) Bayesian analysis of radiocarbon dates. Radiocarbon 51 (1): 337-360.

-Buys S, Oakley V (1993) conservation and restoration of ceramics. Oxford. ButterworthHeinemann. 
-Cronyn JM (1990) The Elements of Archaeological Conservation. Routledge, London.

-Cultrone G, Rodriguez-Navarro C, Sebastian E, Cazalla O, De La Torre MJ (2001) Carbonate and silicate phase reactions during ceramic firing. Eur J Mineral 13(3): 621-634.

-Davidson A, Brown GW (2012) Paraloid TM B-72: practical tips for the vertebrate fossil preparatory. Collec Forum 26: 99-119.

-Dowman E (1970) conservation in the field archaeology. Methuen, London.

-Fadda, E (1991) The geology of the Sahab area, map sheet No. 3253 IV. Ministry of Energy and Mineral Resources, Natural Resources Authority, Amman.

-Franken HJ (1992) Excavations at Tell Deir Alla: The Late Bronze Age sanctuary. Peeters, Louven.

-Glanzman WD, Fleming SJ (1986) Pottery technology: fabrication methods. In: McGovern PE(ed) The Late Bronze and early Iron Ages of central Transjordan: the Baq'alz Valley project 1977-1981. University Museum Monograph 65, University Museum, Philadelphia, pp 164-77.

-Grim RE (1968) Clay Mineralogy. II edition. McGraw-Hill, New York.

-Ibrahim M (1972) Archaeological excavations at Sahab, 1972. Annu Dep Antiq Jordan 17:2336.

-Ibrahim M (1978) The collared rim jar of the Early Iron Age. In: Moorey PRS; Parr P (eds) Archaeology in the Levant: essays for Kathleen Kenyon. Aris and Phillips, Warminster, pp. 117-126.

-Killebrew A (1998) Ceramic typology and technology of Late Bronze II and Iron I assemblages from Tel Miqne-Ekron: the transition from Canaanite to Philistine culture. In: Gitin S; Mazar A; Stern E (eds) Mediterranean Peoples in Transition: Thirteenth to Early Tenth Centuries BCE. Israel Exploration Society, Jerusalem, pp 379-405.

-Koob SP (1986) The use of Paraloid B-72 as an adhesive: its application for archaeological ceramics and other materials. Stud Conserv 31(1): 7-14.

-Maggetti M (1994) Mineralogical and petrographic methods for the study of ancient pottery. In: Burragato F; Grubessi O; Lazzarini L (eds) First European Workshope on Archaelogical Ceramics. Università degli Studi di Roma "La Sapienza", Rome, pp 23-35.

-Maniatis, Y (2009) The emergence of ceramic technology and its evolution as revealed with the use of scientific techniques. In: Shortland, A.J., Freestone, I.C., Rehren, T. (Eds.), From mine to microscope: Advances in the study of ancient technology. Oxbow Books, Oxford, pp. 1128.

-Maritan, L., Nodari, L., Mazzoli, C., Milano, A. and Russo, U. (2006) Influence of firing conditions on ceramic products: experimental study on clay rich in organic matter. Applied Clay Science 31(1): 1-15.

-MB, Skibo JM (1987) Theory and experiment in the study of technological change. Curr Anthropol 28(5): 595-618.

-Peterson SE, Betancourt PP (2009) Thin-section petrography of ceramic materials. INSTAP Academic Press, Philadelphia. 


\section{Archaeometric characterization and conservation of two Bronze-Iron Age jars from Sahab archaeological site, Jordan}

-Plenderleith HJ, Werner AE (1971) The conservation of antiquities and works of art: treatment, repair and restoration. Oxford University Press, Oxford.

-Reimer PJ, Baillie MGL, Bard E, Bayliss A, Beck JW, Blackwell PG, Bronk Ramsey C, Buck CE, Burr GS, Edwards RL, Friedrich M, Grootes PM, Guilderson TP, Hajdas I, Heaton TJ, Hogg AG, Hughen KA, Kaiser KF, Kromer B, McCormac FG, Manning SW, Reimer RW, Richards DA, Southon JR, Talamo S, Turney CSM, van der Plicht J, Weyhenmeyer CE (2009) IntCal09 and Marine09 radiocarbon age calibration curves, 0-50,000 years cal BP. Radiocarbon 51: 1111-1150.

-Riccardi MP, Duminuco P (1999) An approach to the dynamics of clay firing. Appl Clay Sci 15(3): 393-409.

-Rice, M. (1987) Pottery analysis: A sourcebook. The University of Chicago Press/Chicago and London.

-Rye OS (1981) Pottery technology: principles and reconstruction. Taraxacum, Washington DC.

-Shoval S, Beck P, Yadin E (2006) The ceramic technology used in the manufacture of Iron Age pottery from Galilee. Special Publication- Geological Society of London 257: 101-117.

-Smith S (1998) British Bronze age pottery; an overview of deterioration and current techniques of conservation at the British museum. The Conservator 22(1): 3-11.

-Stilborg O (2001) Temper for the sake of coherence: Analyses of bone- and chaff-tempered ceramics from Iron Age Scandinavia. Eur J Archaeol 4(3): 398-404.

-Tite MS, Freestone IC, Meeks ND, Bimson NM (1982) The use of scanning electron microscopy in the technological examination of ancient ceramics. In: Olin JS, Franklin AD (eds) Archaeological Ceramics. Smithsonian Institution Press, Washington DC, pp 109-120.

-Tite MS, Maniatis Y (1975) Examination of ancient pottery using the scanning electron microscope. Nature 257: 122-123.

-Tubb J, Dorell P, Cobbing E (1996) Interim report on the eighth (1995) season of excavation at tell es-Sa'idiyed. Palest Explor Q 128:16-40.

-Walker W (1996) Gap-filling friable ceramics with microballoons and Paraloid B-67. Stud Conserv 41( Supplement-2): 29.

-Wood BG (1990) The sociology of pottery in ancient Palestine: the ceramic industry and the diffusion of ceramic style in the Bronze and Iron Ages. Adam and Charles Black, London, JSOT/ASOR Monograph 4. 